\title{
The Contribution and Legacy of Academician V.A. Koptyug to the International Union of Pure and Applied Chemistry (IUPAC)
}

https://doi.org/10.1515/pac-2018-0302

\begin{abstract}
Valentin Koptyug (1931-1997) was President of IUPAC during the 1987/89 biennium. In addition to his immense service to the educational, scientific and economic development of his own country Professor Koptyug made outstanding contributions to IUPAC over many years as well as to the other international organisations which he served. His interest in and dedication to the preservation of the environment and to the principles of sustainable development came very early. As a consequence, his influence has extended over many years. His inspiration has motivated IUPAC to greatly broaden the scope of its work and to collaborate with other international organisations to tackle real problems of societal interest.
\end{abstract}

Keyword: ICGC-7.

\section{Introduction}

The seventh in the series of the International Union of Pure and Applied Chemistry (IUPAC) International Conferences on Green Chemistry was hosted by the D. I. Mendeleev University of Chemical Technology in Moscow, Russian Federation, from October $2^{\text {nd }}$ to the $5^{\text {th }}, 2017$. Among the special symposia in its programme was one dedicated to the memory of Academician V. A. Koptyug who, among his many other distinguished achievements, had served as President of IUPAC for the 1987/89 biennium. Koptyug's contributions to IUPAC of course encompassed a much longer period than this. Over the years he served in various offices in the Union and coupled with his extensive efforts in several other international scientific agencies he is now seen as having exerted major influences on the manner in which these organisations thought and developed and presented themselves to and influenced the world's chemistry community over the past three decades. As we approach the centenary of the foundation of IUPAC in Paris in 1919 it is fitting that we should explore Valentin Koptyug's work and, in particular, how it has shaped pertinent modern extensions to the areas in which IUPAC has developed its interests and expertise. These changes have greatly increased knowledge of the relevance of Chemistry in the world as well as extending the work of the Union to more general and immediate societal interests and to starting to build solutions for several of the major problems facing humanity.

Several contributions at the special symposium described the very extensive work that Valentin Koptyug accomplished in his own country during a lifetime spent in the service of scientific endeavour. He received his higher education at the Mendeleev University of Chemical Technology, graduated as a Ph.D. in 1957 and worked from 1959 onwards in the Siberian Branch of the Russian Academy of Sciences. In 1965 he published

Article note: A collection of invited papers based on presentations at the $7^{\text {th }}$ International IUPAC Conference on Green Chemistry (ICGC-7), Moscow, Russia, 2-5 October 2017.

*Corresponding author: John Corish, School of Chemistry, Trinity College Dublin, University of Dublin, Dublin 2, Ireland, e-mail: jcorish@tcd.ie 
his D.Sc. Thesis and in 1968 he became a professor and corresponding member of the USSR Academy of Sciences (later the Russian Academy of Sciences). Between 1978 and 1980 he was President of the Novosibirsk State University and during that period became a member of the Russian Academy of Sciences. In 1980 he was elected Academy Vice-President and Head of the Siberian Branch of the Academy and in 1987 he was also appointed as Head of the Novosibirsk Institute of Organic Chemistry. His research interests were extraordinarily wide-ranging covering both fundamental and applied aspects of physical and organic chemistry and with a special interest in new physical methods, mathematical modelling and the development and utilisation of data bases in research practice. Everything that he did was, however, permeated by a deep and abiding interest in ecological science and he sought always to protect the environment while never failing to champion sustainable development. He believed strongly in the value and power of science and particularly of chemistry to advance society while insisting that it was always necessary to keep in mind the three principles of social development, economic development and environmental conservation. Most notable among his accomplishments in his own country was the network of scientific centres that were established and that flourished in Siberia during and following his time as Head of the Siberian Branch of the Academy and his tireless work to prevent the transfer of water from northern rivers to the south and particularly the preservation of fresh water in Lake Baikal.

Here we shall concentrate on an assessment of his contributions to the world which were made through his dedicated service to several international organisations. These efforts were initiated through his long service to IUPAC. We shall discuss the principal areas of chemical sciences in which he worked and which subsequently became established in the Union. His influence then extended more widely because of his service to other international agencies such as the International Council of Scientific Unions (ICSU) and the United Nations (UN). We shall explore why and how his work has exerted such a major and lasting influence in these international organisations and through them into the world at large.

\section{The early years in IUPAC}

Professor Koptyug first joined IUPAC in 1973 becoming a member of Commission I.5, the Commission on Molecular Structure and Spectroscopy, in the Physical Chemistry Division. In this capacity he completed a novel project on the development of electronic data bases for the properties of chemical compounds. He was first elected to the Bureau, part of the governing structure of the Union, at the Davos General Assembly in 1979. As a Bureau Member, and later as an Officer, he spearheaded and greatly influenced the Union's responses to the increasing global significance of environmental problems. He also initiated efforts to restructure the Union's activities to adequately reflect the global changes then occurring and to apply scientific knowledge to solving emerging difficulties. He was seen by his contemporaries as a man from the future living in an earlier epoch. His thinking was always notably outward-looking and because it came ahead of its time his influence naturally continued to be felt for many years. He was elected as Vice-President (President-Elect) of IUPAC at the Lyon General Assembly in 1985 and succeeded to the Presidency at Boston 2 years later. He then served the term 1989-1991 as immediate Past-President. At the General Assembly in Lund in 1989 at which he presided as President, Professor Koptyug said 'Concerning environmental problems IUPAC will have to become more enthusiastically involved in the activity of the world community - first of all within the framework of the United Nations Environment Programme'. This statement illustrates well both his great interest in protecting and maintaining the environment and his determination to take the benefits of interdisciplinary science out into mainstream society. At that General Assembly it was proposed that the work of a number of the IUPAC Commissions be coordinated with the efforts of the ICSU Scientific Committee on Problems of the Environment (SCOPE). As we shall see his initiative in environmental chemistry continued to have a major impact on the work of IUPAC in the years that followed - in fact to the present day - particularly regarding protection and improvement of the environment for society. The concern expressed by President Koptyug that IUPAC should be proactively engaged in the chemistry of the environment prompted an immediate follow-up review of all relevant work currently being done in the Union. This was carried out by the then Information Officer 
Michael Freemantle and was published as a booklet in 1990 entitled 'Chemistry and the Environment: the IUPAC Programme'. This clearly revealed that a considerable amount of work was being done on the chemistry of soils, air, water and agrochemicals and following discussion by the Division Presidents during the $38^{\text {th }}$ General Assembly at Guilford in 1996 the Council designated the Applied Chemistry Division as the Division of Chemistry and the Environment with redefined terms of reference. Koptyug's influence was continuing to guide the progress of the Union.

Indeed, in addition to the new Division, extensive work related to the interaction of chemistry with the environment continued in other Divisions and units particularly, for example, in the extensive and successful CHEMRAWN (CHEMical Research Applied to World Needs) programme. Always a rigorous supporter of the programme's activities Professor Koptyug working with Professor Oleg Nefedov organised the CHEMRAWN VII Conference on 'Chemistry and Sustainable Development Towards a Clean Environment' held in Moscow in 1992. At the General Assembly in Geneva in 1997 President Fischli noted and welcomed the fact that the formal involvement of IUPAC with chemistry and the environment was already promoting interactions with several other international organisations. The developing ethos led to initiatives such as the Strategic Committee on Materials which organised a programme on new materials at the United Nations Educational Scientific and Cultural Organisation (UNESCO)/ICSU World Science Conference in Budapest in 1999.

\section{Beyond IUPAC on the world scene}

After his Presidency of IUPAC Professor Koptyug was appointed as IUPAC representative to the ICSU-SCOPE Committee (1989-1997) and became its Vice-President in 1992. Here he proactively promoted the concept of sustainable development. He represented his country as head of the science group at the landmark UN Conference in Rio de Janeiro in 1992 on Environment and Development often referred to as the 'Earth Summit'. He was later distinguished as the recipient of an Honours Certificate from the United Nations to recognise his contributions to this meeting and to the subsequent realisation of its objectives. The concept of sustainable development emanating from this notable meeting came to be recognised as the fundamental principle in the development for the human community and has recently become of crucial importance as enshrined in the UN declaration of its 17 Sustainable Development Goals (SDG) in 2015.

Another scientific and ethical issue that was adopted vigorously about this time by IUPAC was the question of the use of chemical weapons. This was raised by the National Adhering Organisation of Greece with the IUPAC Executive Committee at Geneva and with the Council at Lund in 1989. Subsequently Professor Koptyug strongly supported a proposal from one of his successors, President Bard, that the detoxification of chemical weapons was a proper matter for the attention of IUPAC experts. IUPAC did considerable valuable work with an internal Task Force, later constituted as an ad hoc Committee of the Bureau that contributed until 1999. It also acted through ICSU on the Scientific Aspects of the Destruction of Chemical Weapons. Indeed, it is interesting to note that ICSU at that time established a standing Committee on Responsibility and Ethics in Science. IUPAC provided expert advice on the impact of scientific developments on the Chemical Weapons Convention and collaborated on this topic with the Organisation for the Prohibition of Chemical Weapons (OPCW) which was awarded the Nobel peace Prize in 2013 for its efforts.

\section{New horizons for IUPAC}

In its almost one-hundred-year history IUPAC has long established itself as the globally-recognised authority on chemical nomenclature as well as providing accepted standards and recognised data collections on all aspects of the chemical sciences. However, IUPAC in more recent years has also greatly broadened its scope and interests by providing objective scientific expertise for the resolution of crucial global issues. As early as 1977 in his report on the state of the Union address in Warsaw President Cairns had stated 'The future 
well-being of the Union is for the first time critical in the fulfilment of world needs - in the past we have prided ourselves on the fulfilment of the needs of world scientists. Now the world has advanced to such a stage of development that science is an essential component part of the world structure along with politics, law, economics and other human factors, science seems to stand alone as an arbiter of human survival. We, as Chemists have an essential role to play in this drama'. In the 40 years since this statement was made IUPAC has responded by broadening the scope of its work from the purely scientific to encompass the most important relevant applications of science through all human society. It has established Divisions and other instruments to deal with the chemistry of the environment, clinical chemistry, human health, chemical education, and, most recently, green chemistry and sustainable development. It has developed and fostered an outward-looking ethos to enable and encourage an innovative and broader presence for chemistry. Through almost all of this, the remarkable foresight and keen judgement of President Koptyug, coupled with his international standing and leadership has set him aside as the inspiration and most influential instigator of these developments in the Union and its work.

Many initiatives were undertaken, especially in the period 1975-2000, to alter the modus operandi of IUPAC to allow it to more easily adapt to the changes in the manner in which chemistry was advancing and to enable the Union to take on new broader interests that would make real contributions to societal problems. These included horizontal as well as the traditional work programmes, limited lifetime Commissions to undertake specific tasks and bespoke interdisciplinary initiatives. In addition to serving the classical traditional sub-sections of the subject new Divisions and Standing Committees were dedicated to applied areas with societal interest such as the chemistry of human health. In a very major restructuring in 2000 all the 37 permanent Commissions, each of which had reported to one of the Divisions, were discontinued and the scientific and other work of the Union was transferred to a project-driven model. The project teams were funded only for the length of time necessary to complete each task undertaken and to present a report. The Union also sought to widen its spheres of influence through partnerships with other kindred international organisations - ICSU, UNESCO, OPCW - to assert the place of Chemistry in all of human life.

This broadening of the arenas in which IUPAC operates has continued and accelerated since and has led to initiatives such as the International Year of Chemistry, which was designated by the United Nations for 2011. The many activities and celebrations, which took place all over the world after the official opening in Paris, were organised jointly by IUPAC and UNESCO. The very successful year greatly increased public appreciation of the place of chemistry in meeting world needs. IUPAC is also beginning to work with SAICM (Strategic Approach to International Chemicals Management) where it sees a role for an authoritative independent science input in the work of promoting chemical safety around the world. It continues to endorse and assist the OPCW ethical guidelines which require the production and use of chemicals to be accompanied by recognition of the responsibility of chemists to ensure that they are applied solely for peaceful and beneficial purposes.

\section{A profound and long-lasting influence}

The question naturally arises as to the reason that the influence of Valentin Koptyug on IUPAC and on the scope of its work was so large and why it has lasted for so many years? There are several answers the first of which is that the topics espoused by Koptyug were very erudite and focussed on key fundamental areas in the relationship of science with society: chemistry and the environment and sustainable development. Their significance was further strengthened by the fact that they were introduced at a period when they were concepts that were very far in advance of their time and therefore immediately engendered a wide interest. And they were enhanced by an outwards-focussed ethos on the societal responsibility of science coupled with its unique ability to provide workable answers. They were driven by a profound belief that science would save humanity. Koptyug's later extensive work with ICSU and with the UN Sustainable Development Advisory Council, to which he was appointed by the UN Secretary General, Boutras Ghali, was another major factor in bringing these areas to the fore among the world's scientific community. He had a great capacity for effective 
work coupled with an ability to collaborate constructively with others in an international context and his foresight and initiatives continue to bear fruit today. The current strategic plan of IUPAC, https://iupac.org/ who-we-are/strategic-plan/ which was put in place in 2015 after an extensive review, specifically states that the mission of the Union will be accomplished by fostering sustainable development as well as providing a common language for chemistry and advocating free exchange of scientific information. The new Interdivisional Committee on Green Chemistry for Sustainable Development, https://iupac.org/body/041 which was set up at the General Assembly in San Paulo only last year, is embarking on a major programme that includes conferences and summer schools, outreach to other international organisations as well as to the international chemistry industry and will develop metrics for green synthesis. The Hague Ethical Guidelines, which were enunciated in 2015, https://www.opcw.org/special-sections/science-technology/the-hague-ethicalguidelines are a set of ethical guidelines related to the Chemical Weapons Convention. IUPAC was actively engaged in the formulation of these guidelines and has formally endorsed them. Core elements include the requirements that achievements in the field of chemistry should be used to benefit humankind and protect the environment and that chemical practitioners have a special responsibility for promoting and achieving the UN Sustainable Development Goals. And more recently, in 2016, OPCW and IUPAC took their partnership to a new level by signing a Memorandum of Understanding https://www.opcw.org/news/browse/185/article/ opcw-and-international-union-of-pure-and-applied-chemistry-take-partnership-to-new-level/ pledging to enhance cooperation to keep abreast of developments in chemistry, responsibility and ethics in science, and education and outreach. And even into the future the UN General Assembly, during its Plenary Meeting in December 2017, has proclaimed 2019 as the International Year of the Periodic Table of Chemical Elements (IYPT) https://iupac.org/united-nations-proclaims-international-year-periodic-table-chemical-elements/. The IYPT will coincide with the IUPAC Centenary and will present a worldwide stage on which to display how the chemical elements are central to linking culture, economics and political aspects of the global society through a common language. It is endorsed by a number of International Scientific Unions and by the International Council for Science (ICSU) and is exemplary of Academician Koptyug's belief in an interdisciplinary approach and in the vital role that science plays in the advancement of human society.

\section{Acknowledged sources}

R. Fennell, History of IUPAC1919-1987, Blackwell Science, 1994.

B. F. Myasoedov, Chemistry International, 23, (5) 2001.

S.S. Brown, History of IUPAC 1988-1999, International Union of Pure and Applied Chemistry 2001.

Science: First Hand, 12.11.2015.

N. L. Dobretsov, https://scfh.ru/en/papers/lessons-from-koptyug/. 